http://jmscr.igmpublication.org/home/ ISSN (e)-2347-176x ISSN (p) 2455-0450

crossref DOI: https://dx.doi.org/10.18535/jmscr/v7i12.15

\title{
Cross Sectional Study of Cardiovascular Effects in Acute Ishaemic Stroke
}

Authors

\author{
Dr Balakrishna GT ${ }^{1}$, Dr K Sudheer ${ }^{2}$, Dr Sarma VSN Rachakonda ${ }^{3}$, \\ Dr A Sridhar ${ }^{4}$ \\ ${ }^{1}$ Postgraduate, Department of General Medicine, GEMS. \\ ${ }^{2}$ Head of Medicine Department, GEMS. \\ ${ }^{3}$ Professor, Department of Medicine, GEMS. \\ ${ }^{4}$ Assistant Professor, Department of mMdicine, GEMS. \\ *Corresponding Author \\ Balakrishna GT
}

\section{Introduction}

Cerebrovascular accident (CVA) or stroke is the third leading cause of death in the developed countries after cardiovascular disease and cancer 1 Cerebral infarction is responsible for about $80 \%$ of all first ever in a lifetime strokes- Primary intracerebral hemorrhage $(\mathrm{PICH})$ for $10 \%$ and subarachnoid hemorrhage for $5 \%$.

The incidence of stroke worldwide is 179 per $1,00,000$ population in various parts.

A significant number of stroke patients are having coexistent cardiac abnormalities.

\section{Aim of the study}

To find the association between cardiac abnormalities (both symptomatic and asymptomatic) and ischemic stroke, in terms of clinical parameters, ECG, ECHO and other ancillary investigations.

\section{Methodology}

The material of the study comprised 50 patients admitted in GEMS Hospital, Srikakulam, between November 2017 to September 2018.

\section{Inclusion Criteria}

- Age above 18 years.

- Presence of acute ischemic stroke proven by CT/MRI Brain.

\section{Exclusion Criteria}

- Age below 18 years.

- Patients with known cardiac disease.

- Patients with previous cerebrovascular accident.

- Chronic kidney disease patients.

\section{Method of Data Collection}

After admission a detailed history regarding the temporal profile of the stroke including risk factors like hypertension, diabetes mellitus, smoking, history of ischemic heart disease and rheumatic heart disease were obtained. Detailed neurological examination including fundoscopy and cardiovascular examination were carried out in all the cases.

The diagnosis of CVA was made on the basis of the following criteria:

1) Temporal profile of clinical syndrome. 
2) Clinical examination.

3) CT/MRI Brain.

4) A 12 lead ECG and 2D Echocardiography was done within $24 \mathrm{hrs}$ of admission.

\section{Statistical Analysis}

The collective data as well as the proportions and percentages of variables are projected by appropriate charts, tables and graphs.

The statistical data analysis was done by chi square test.

\section{Results}

During the study period from Nov 2017 to September 2018, those who met the inclusion and exclusion criteria were included in the study. A total of 50 patients were analyzed in the study.

\section{Distribution of Patients by Age and Sex}

Below table shows that female predominance with mean age of 51-70 years

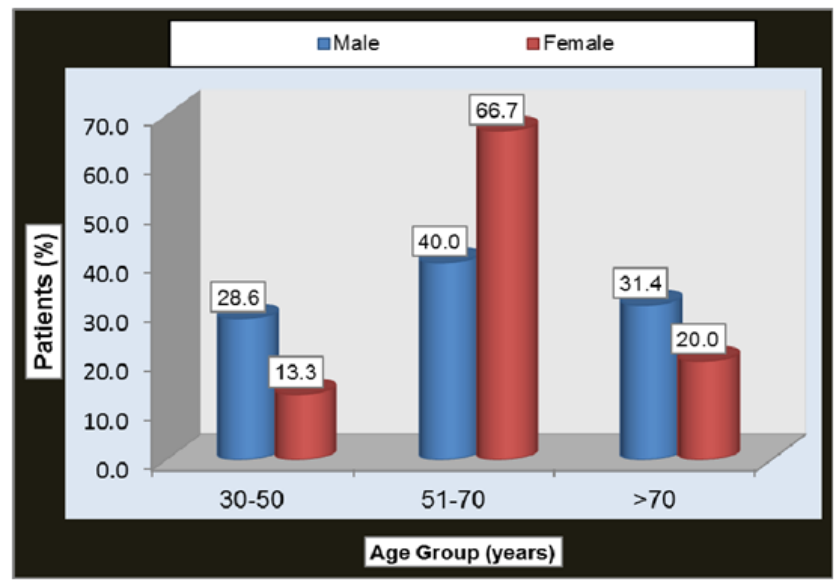

\section{Cardiac Symptoms in Stroke Patients by Sex:}

Below table shows that most common symptom is chest pain with male predominance.

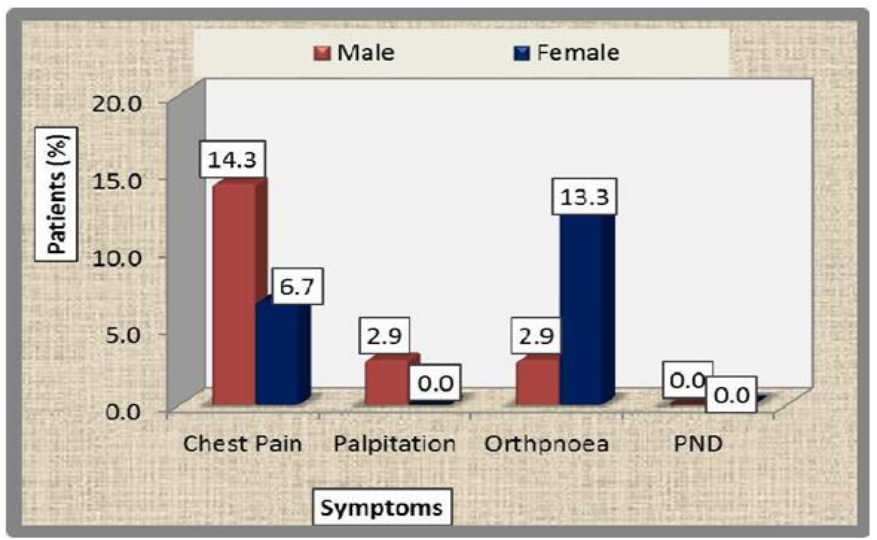

\section{Risk factors in Stroke Patients by Sex}

Below table shows that most common risk factor is hypertension with male predominance.

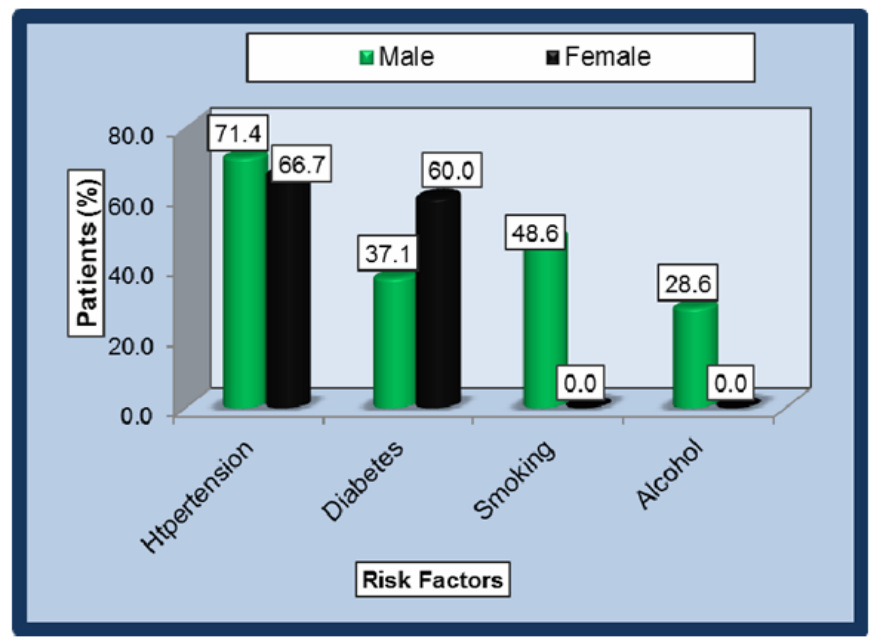

ECG Changes in Stroke Patients by Sex

Significant ECG changes were $\mathrm{T}$ wave inversion with female predominance.

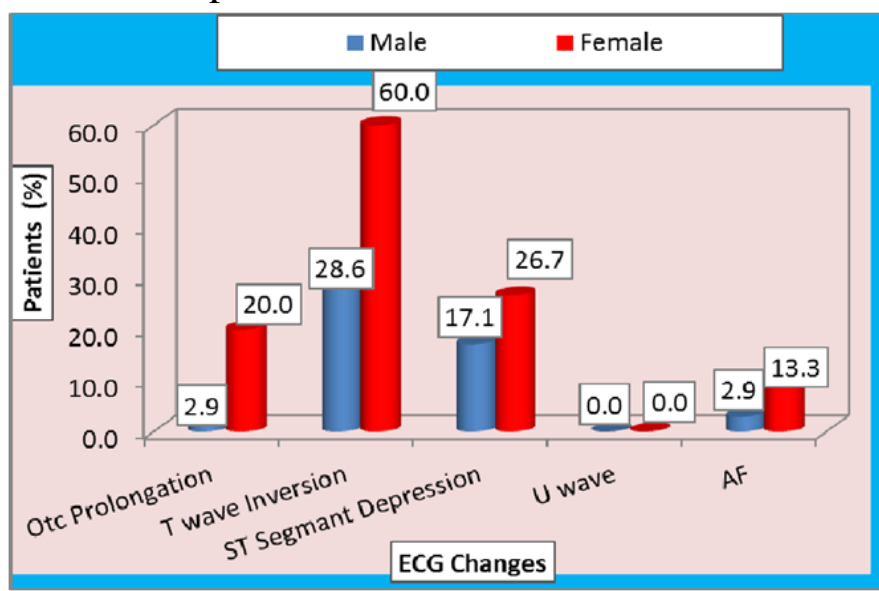

\section{D Echo findings in stroke patients by sex}

Below table shows the most common 2D Echo abnormality is diastolic dysfunction

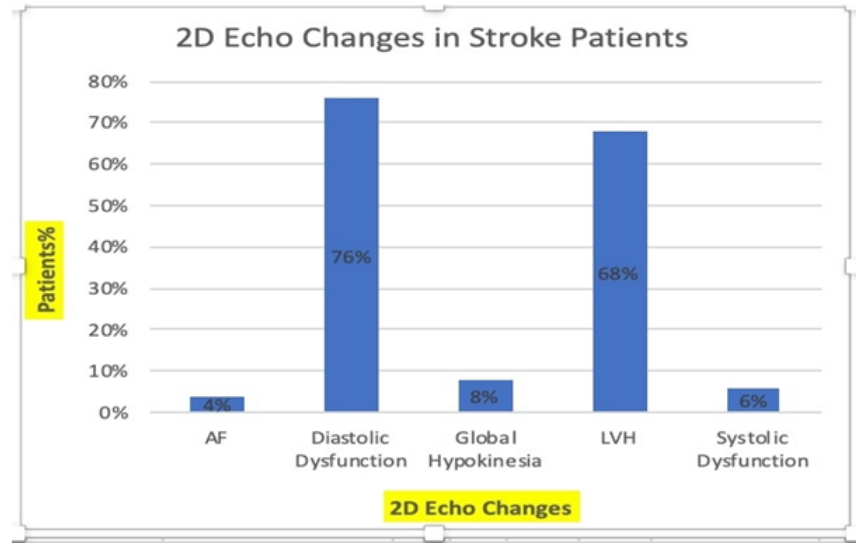




\section{Cranial Imaging of Stroke Patients by Sex}

Below table shows that Middle cerebral artery (MCA) is most commonly involved than anterior cerebral artery (ACA) and vertebral basilar artery (VBA).

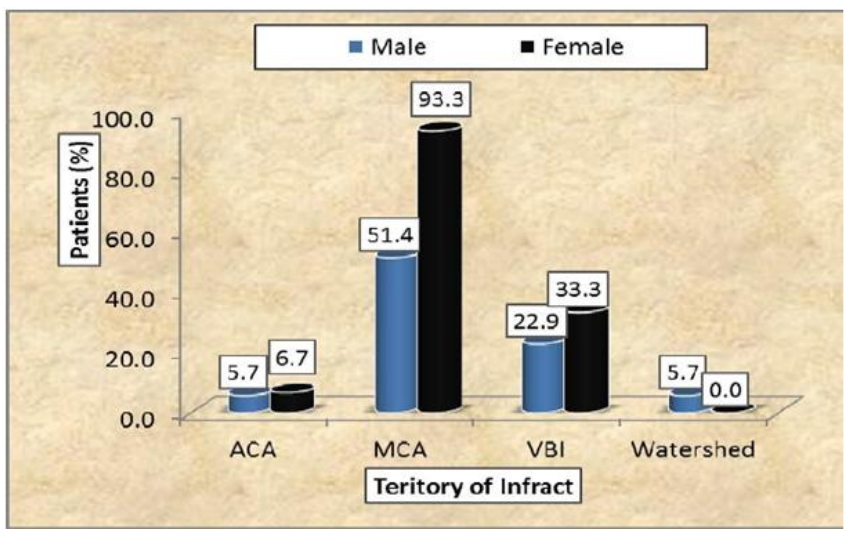

\section{Summary}

Peak incidence of age is between $5^{\text {th }}$ to $7^{\text {th }}$ decades.

Male to female ratio is- 7:5.

Commonest presenting symptom being weakness of the limbs, followed by altered sensorium, speech abnormality.

Commonest presenting cardiac symptom being chest pain (12\%), followed by orthopnea, palpitations and Paroxysmal nocturnal dyspnea (PND), which was statistically not significant.

Commonest vascular territory involved is MCA territory $(8 \%)$, which was statistically significant, followed by ACA, VBI and Watershed infarct. Hypertension was the most common risk factor comprising of $70 \%$, followed by diabetes mellitus, alcohol and smoking.

The most common ECG changes were $\mathrm{T}$ wave inversion, ST-T wave changes, LVH (left ventricular hypertrophy).

Echocardiographic changes were LVH in $68 \%$, Diastolic dysfunction in $76 \%$, Global hypokinesia in $8 \%$, Mitral stenosis (MS) in $2 \%$, Left atrial (LA) clot in $2 \%$.

\section{Conclusion}

A total of 50 subjects were studied for cardiac abnormalities by means of history, risk factors, ECG, 2D Echo. Hypertension, DM and smoking were the most common risk factors with varied findings in ECG and 2D Echo from T-wave inversion to ST segment elevation and diastolic dysfunction to global hypokinesia.

Thus this study underlies the importance of studying the cardiac abnormalities in patients of acute ischemic stroke which would help early recognition of the same and in-turn better treatment of patients which helps in decreasing mortality and morbidity of these patients.

\section{References}

1. Jane Prosser, Lachlan MacGregor et al. Predictors of Early Cardiac Morbidity and Mortality After Ischemic Stroke. Stroke 2007,38: 2295-2302.

2. M.S. Dhamoon, MD, MPH; R.R. Sciacca, Eng $\mathrm{ScD}$ et al. Recurrent stroke and cardiac risks after first ischemic stroke. NEUROLOGY 2006; 66;641-646. 